\title{
Persistent Hypothermia and Excessive Sweating Following Intrathecal Morphine Administration in a Teenage Boy: A Case Report Sara Ferraz, ${ }^{1, *}$ Telma Caria, ${ }^{2}$ Aline Vaz Da Silva, ${ }^{3}$ Maria Jose Candeias, ${ }^{4}$ and Teresa Cenicante ${ }^{4}$
}

${ }^{1}$ Anaesthesiology Department of Centro Hospitalar de Vila Nova de Gaia/Espinho, Vila Nova de Gaia, Portugal

${ }^{2}$ Anaesthesiology Department of Centro Hospitalar Lisboa Ocidental, Lisboa, Portugal

${ }^{3}$ Pediatric Surgery Department of Centro Hospitalar Lisboa Central, Hospital Dona Estefânia, Lisboa, Portugal

${ }^{4}$ Anaesthesiology Department of Centro Hospitalar Lisboa Central, Hospital Dona Estefânia, Lisboa, Portugal

"Corresponding author: Sara Ferraz, Anesthesiology trainee at Centro Hospitalar de Vila Nova de Gaia/Espinho, Rua Jose Joaquim Gomes da Silva, 59 - 6 Direito; $4460-171$ Matosinhos, Porto, Portugal. Tel: +35-1917468963, E-mail: sara.ferraz.lf@gmail.com

Received 2018 January 31; Accepted 2018 February 17.

\begin{abstract}
Introduction: Opioids are used intrathecally to manage surgical pain. There are few reports of hypothermia after spinal morphine injection, none in the pediatric population. We present a teenager's case of mild hypothermia.

Case Presentation: A15-year-old boy was scheduled for elective abdominal laparotomy. General anesthesia was combined with spinal anesthesia, using levobupivacaine and morphine. In the recovery room, he presented a decreased tympanic temperature $\left(34.4^{\circ} \mathrm{C}\right)$ associated with excessive sweating, hyperglycemia, and complained of feeling hot. All other vital signs were normal. It was decided to maintain clinical vigilance and hourly monitoring of temperature and glycaemia values. Despite active warming, he remained hypothermic for 16 hours, with gradual remission of symptoms and normalization of glycemic values. It is unknown how intrathecal morphine causes hypothermia. The most viable hypothesis is its effect on the hypothalamus. In our case the most probable causes of post anesthesia hypothermia were excluded; therefore, we can admit that the cause of hypothermia was the spinal administration of morphine. Some reports used naloxone and lorazepam successfully. In our report, they disappeared spontaneously 16 hours later, which corroborates our diagnosis.

Conclusions: Children undergoing subarachnoid block with with intrathecal morphine may develop a disruption on thermoregulation, leading to a resistant postoperative hypothermia associated with excessive sweating.
\end{abstract}

Keywords: Anesthesia, Spinal, Pediatric Anesthesia, Hypothermia, Morphine

\section{Introduction}

Opioids are often administered intrathecally to manage intra and postoperative pain. Its popularity for pediatric patients has increased. It provides intense, safe, and prolonged postoperative analgesia (1).

Intrathecal morphine has advantages as it decreases the need for postoperative opioids and it has a long duration of action, by its administration at its site of real actioncentral nervous system, which is mediated by its action on the opioid receptors in the spinal cord. Although there is a higher tolerance this way, adverse effects such as nausea and vomiting, sedation, as well as respiratory depression are still present (2). Hypothermia, described as a consequence of subarachnoid blockade, mainly by vasodilation, may be associated with morphine intrathecal administration.

There are few cases described, most of them in the obstetric population submitted to cesarean cession and 1 in an orthopedic patient (3). There is none in the pediatric population.

We present a case of hypothermia in a teenage boy after intrathecal administration of morphine.

\section{Case Presentation}

A 15-year-old boy (body weight $49 \mathrm{~kg}$, height $181 \mathrm{~cm}$ ), ASA physical status II (allergic rhinitis, frequent epistaxis) was scheduled for elective surgery of a pelvic mass resection. Besides anemia $(9.3 \mathrm{~g} / \mathrm{dL})$ and an increased platelet count $\left(592 \times 10^{9} / \mathrm{L}\right)$ his blood tests were normal.

After premedication with oral midazolam, the boy was taken to the operating room. Electrocardiogram, noninvasive blood pressure, pulse oximetry, and pediatric bispectral index sensor were used and his vitals were stable. After establishing peripheral intravenous (IV) access, 500 $\mathrm{mL}$ of Ringer's Lactate was started and an induction of intravenous general anesthesia with fentanyl, propofol, and rocuronium was performed following maintenance with sevoflurane.

Next, a right radial artery line was placed followed by an ultrasound guided central venous catheter in the right brachiocephalic vein, without intercurrences.

The teenage boy was then placed in a lateral decubitus position and a subarachnoid block (SAB) was performed under an ascetic technique with a $27 \mathrm{G}$ quincke needle. A median approach was successfully performed after a single puncture at the L3 - L4 level. Correct placement of the 
needle was verified by a free flow of clear cerebrospinal fluid. Hyperbaric bupivacaine $0.5 \%$ (total $7.5 \mathrm{mg}$ ) plus morphine $0.200 \mathrm{mg}(0.4 \mathrm{mcg} / \mathrm{kg})$ were used for SAB.

The child was positioned in dorsal decubitus, $1960 \mathrm{mg}$ of cefazolin IV was administered and active warming was started using a forced-air warming system.

The patient's vitals were stable during the whole surgery, which lasted for 1 hour and 30 minutes and was eventless. His tympanic temperature (TT) was $35^{\circ} \mathrm{C}$ at the end of surgery.

About 20 minutes after arriving at the recovery room, nearly 2 hours after the SAB, the boy presented a decreased TT $\left(34.4^{\circ} \mathrm{C}\right)$ associated with excessive sweating, no shivering, hyperglycemia, nausea and complained of feeling hot. All other vital signs, complete blood count and electrolytes were normal. An antiemetic was administered with resolution of nausea. Warm blankets and active warm were implemented.

One hour later, the boy was discharged from the recovery room. His vitals were stable and his TT was $34.5^{\circ} \mathrm{C}$ and he was feeling more comfortable.

The emergency team was called about 5 hours later because the boy was still hypothermic (TT $34.0^{\circ} \mathrm{C}$ and axillar temperature (AT) $33.9^{\circ} \mathrm{C}$ ) and sweating. Hyperglycemia remained (201 mg/dL). All his vitals were normal and his diuresis was preserved $(0.8 \mathrm{~mL} / \mathrm{kg} / \mathrm{h})$. It was decided to warm the patient with a forced air system, maintain clinical vigilance and hourly monitoring of temperature and capillary glycemic values.

Despite all the measures, temperature maintained below $36^{\circ} \mathrm{C}$ for the next 16 hours $\left(33.8^{\circ} \mathrm{C}-35.4^{\circ} \mathrm{C}\right)$, with gradual remission aapaapm of symptoms and normalization of glycemic values.

We excluded the most probable causes of post anesthesia hypothermia (hypovolemia, environmental conditions or infection). His symptoms were considered to be secondary to the intrathecal morphine, as we consulted medical literature and found that some similar cases have been reported in adult patients. Some of them used naloxone or flumazenil to reverse symptoms successfully (2-6), however, our attitude was to maintain clinical vigilance. In our clinical case, the symptoms disappeared 16 hours later, without pharmacotherapy, which favors that the cause of hypothermia was due to intrathecal morphine.

\section{Discussion}

The core temperature (CT) is one of the most rigorously controlled physiological parameters of the body and is usually maintained within well-defined limits. The thermoregulatory system allows small variations around $37^{\circ} \mathrm{C}$ for the maintenance of its optimal metabolic and homeostatic functions.

Hypothermia is defined as a CT inferior to $36^{\circ} \mathrm{C}$. CT monitoring during anesthesia provides the early detection of hypothermia that is associated with numerous complications (7).

The temperature of the skin changes according to the temperature of the environment. However, the temperature of the deep tissues remain constant. This is achieved due to our thermoregulatory system, which is organized into afferent pathways, integrative center, and efferent pathways, being that the hypothalamus is the primary thermoregulatory center integrating the various afferent inputs coordinating the responses required to maintain normothermia. The exact way the body establishes temperature thresholds is unknown, however, it is thought to involve post-synaptic inhibitory potentials modulated by various neurotransmitters such as noradrenaline, dopamine, serotonin, acetylcholine, and prostaglandins. These thresholds vary daily around 0.15 to $1^{\circ} \mathrm{C}$ with various factors, such as circadian rhythm, exercise, and infection. Upon integration, and if the temperature is outside this inter-limb range, a response is triggered.

In addition to exposure of the patient to the operating room's cold, the anesthetized patient is incapable of triggering behavioral responses and is also prone to heat loss through the vasodilator action of anesthetic agents. The heat response threshold is usually well preserved during anesthesia, however, there is a marked linear decrease in the cold threshold with vasoconstriction and shivering when opioids and volatile anesthetics are used. They also have a direct effect on the hypothalamus $(7,8)$.

In $\mathrm{SAB}$, redistribution is the main cause of hypothermia in the surgical patient and is due to vasodilation caused by sympathetic blockade. This effect is maximal during the first 30 to 60 minutes and is dependent on the extent of the blockade. Another mechanism leading to hypothermia in these patients is the loss of thermoregulatory vasoconstriction below the level of the blockade. In patients undergoing combined anesthesia, the risk of hypothermia will be higher, due to the shivering threshold decrease and the inhibition of vasoconstriction induced by spinal anesthesia (7).

All of these changes explain hypothermia during general or loco regional anesthesia, which can be easily prevented and reversible through active heating (gold standard) (9).

In the case of our patient, the hypothermia maintained after resolution of the sensory blockade, the absence of response to the heating measures performed, and the maladaptive response with sweating can't be explained by subarachnoid blockade alone. 
After research in the literature, it was concluded that the hypothesis would most likely be intrathecal administration of morphine.

The mechanism by which intrathecal morphine produces this effect has not yet been fully elucidated. Some authors have shown that spinal morphine has intensified hypothermia caused by subarachnoid anesthesia in pregnant women submitted to cesarean section and in one case after an elective total knee arthroplasty. All of the patients complained about nausea and diaphoresis (2-6).

It is known that opioids are directly involved in thermoregulation and determine the temperature threshold by interacting with the $\delta$ receptors in the hypothalamus, leading to poorly adaptive responses such as sweating that may exacerbate hypothermia and contribute to a false sense of heat. The hypothermia and sweating observed in our patient may be related to the cephalic dispersion of morphine in the liquid cerebrospinal fluid due to its hydrophilic characteristics, leading to a disturbance of thermoregulation after reaching the $\delta$ receptors in the hypothalamus.

To solve the condition, some authors have successfully administered lorazepam, and it is thought that interaction with GABAA receptors may have modulated thermoregulation in the hypothalamus. There is, however, no evidence to support this approach $(3,4)$.

Other authors have administered naloxone, which is a competitive antagonist of opioid receptors reversing its action. There was resolution of the picture, objectified by the reduction of the sweating, and increase of the corporal temperature after the administration of the same one $(2,5$, $6)$.

\subsection{Conclusion}

We have concluded that if there is hypothermia in a child after a SAB and it does not respond to forced warm air heating, we should suspect that morphine injection may be the leading cause, therefore, it is important to moni- tor intra and postoperative temperature when intrathecal morphine is administered.

\section{Footnotes}

Conflict of Interest: The authors declare no conflict of interest.

Ethical Statement: All the authors meet the requirements of authorship.

\section{References}

1. Ganesh A, Kim A, Casale P, Cucchiaro G. Low-dose intrathecal morphine for postoperative analgesia in children. Anesth Analg. 2007;104(2):271-6. doi:10.1213/01.ane.0000252418.05394.28. [PubMed: 17242079].

2. Giladi Y, Ioscovich Y. hypothermia following intra-thecal morphine injection during cesarean section a case report and literature review. J Anesth Clin Res. 2015;6(527).

3. Ryan KF, Price JW, Warriner CB, Choi PT. Persistent hypothermia after intrathecal morphine: case report and literature review. Can J Anaesth. 2012;59(4):384-8. doi: 10.1007/s12630-011-9650-z. [PubMed: 22161244].

4. Hess PE, Snowman CE, Wang J. Hypothermia after cesarean delivery and its reversal with lorazepam. Int J Obstet Anesth. 2005;14(4):279-83. doi: 10.1016/j.ijoa.2005.02.004. [PubMed:16143507].

5. Sayyid SS, Jabbour DG, Baraka AS. Hypothermia and excessive sweating following intrathecal morphine in a parturient undergoing cesarean delivery. Reg Anesth Pain Med. 2003;28(2):140-3. doi: 10.1053/rapm.2003.50043. [PubMed:12677625].

6. Mach J, Van Havel T, Gadwood J, Biegner MA. Intrathecal OpioidInduced Hypothermia Following Subarachnoid Block With Morphine Injection for Elective Cesarean Delivery: A Case Report. AANA J. 2016;84(1):23-6. [PubMed: 26939385].

7. Sessler DI. Perioperative thermoregulation and heat balance. Lancet. 2016;387(10038):2655-64. doi: 10.1016/S0140-6736(15)00981-2. [PubMed: 26775126].

8. Diaz M, Becker DE. Thermoregulation: physiological and clinical considerations during sedation and general anesthesia. Anesth Prog. 2010;57(1):25-32. quiz 33-4. doi: 10.2344/0003-3006-57.1.25. [PubMed: 20331336].

9. John M, Ford J, Harper M. Peri-operative warming devices: performance and clinical application. Anaesthesia. 2014;69(6):623-38. doi: 10.1111/anae.12626. [PubMed: 24720346]. 